\title{
DUTCH DISEASE EFFECT OF OIL RENTS ON AGRICULTURE VALUE ADDED IN MIDDLE EAST AND NORTH AFRICAN (MENA) COUNTRIES
}

\author{
Nicholas Apergis ${ }^{a}$, Ghassen El-Montasser ${ }^{\text {, }}$, Emmanuel Sekyere $^{c}$, Ahdi N. Ajmi ${ }^{\text {, }}$ \\ Rangan Gupta ${ }^{\mathrm{e}}$
}

${ }^{a}$ Department of Banking and Financial ManagementUniversity of Piraeus, Greece

${ }^{\mathrm{b}}$ Ecole Supérieure de Commerce de Tunis, Université de la Manouba, Tunisia

${ }^{\mathrm{c}}$ Human Science Research Council-EPD, Pretoria, South Africa

${ }^{\mathrm{d}}$ College of Science and Humanities in Slayel, Salman bin Abdulaziz University, Kingdom of Saudi Arabia

${ }^{\mathrm{e}}$ Department of Economics University of Pretoria, Pretoria, 0002, South Africa

\begin{abstract}
This paper investigates the effect of oil rents on agriculture value added in oil producing Middle East and North African (MENA) countries. Annual data from 1970 to 2011, panel cointegration tests by Pedroni (1999), long ran panel causality tests by Canning and Pedroni (2008), and two-step System GMM by Blundell and Bond (1998) are used in this study. We find a negative relationship between oil rents and agriculture value added in the long run, with a rather slow rate of short run adjustment of agriculture value added back to equilibrium after a boom in oil rents. These results indicate that an oil sector boom is associated with a contraction in the agriculture sectors of the countries in the panel in the long run. This is probably attributable to a resource movement effect from other economic sectors to the booming oil sector in these countries. This serves as evidence of a Dutch disease effect of an oil sector boom on agriculture in the MENA countries in this study.
\end{abstract}

Keywords: Dutch disease, oil rents, agriculture value added, Middle East and North African countries

JEL Classification: C33, F31, N55, N57, O53, O55

\section{Introduction}

The term Dutch disease refers to the adverse effects of natural gas discoveries on the manufacturing sector in the Netherlands in the 1960s, essentially through the subsequent appreciation of the Dutch real exchange rate. This terminology has since been used to describe sectoral booms with adverse general equilibrium effects on other sectors of the economy. Even though Meade and Rusell (1957) were credited with the first paper on resource boom paradox, what is now regarded as the core model of the Dutch Disease theory is found in the seminal work of Corden and Neary (1982). In this classic economic model, there is the non-traded good sector (this 
includes services) and two traded good sectors: the booming sector, and the lagging sector, also called the non-booming tradable sector. All output is produced by factors specific to each sector but labour is domestically mobile between all sectors. The boom could be attributed to an exogenous technological improvement specific to the country concerned, a windfall discovery of a new resource which increases in supply, or the booming sector produces specifically for export with no sales at home, and enjoys a relative increase in prices on the world market relative to the price of imports. The discovery of natural resources (oil) is considered in this paper. The booming tradable sector has two effects; a spending effect, a resource movement effect and their resultant spillover loss effects (Larson, 2004).

The spending effect occurs when the boom increases factor incomes in the booming sector. Assuming demand for nontradable goods is income elastic, there will be an increase in demand for nontradables leading to an increase in the relative prices of non tradables as tradable goods face given world prices (Acosta et al., 2007). This worsens the terms of trade of the respective country and consequently its trade deficit. The resource movement effect occurs when labour shifts from the other sectors to the booming sector due to labour mobility. This lowers the output of other sectors and increases the production of the booming sector, in this case the oil sector. As incomes rise, people consume more nontradables leading to an expansion of the nontradable sector. There is an additional shift of labour from the lagging sector to the nontradable sector. Thus the demand and output of the lagging sector drops after the natural resource boom, whiles the demand, output and relative price of nontradables increase after the natural resource boom. This has a real appreciation effect and is the crux of the Dutch disease phenomenon. The spillover loss effect refers to the loss of positive externalities emanating from the decline in the tradable goods lagging sector (Larson, 2004).

There are however a few variations to the core model. If the lagging sector is capital intensive then the movement of labour towards the booming sector and nontradable sector would simply lead to further industrialisation in the lagging sector, in which case there might be no fall in output. Additionally, the core model assumes that the booming sector's product is wholly exported, neglecting the effects of domestic absorption. However oil is both consumed in the domestic markets of producing countries as well as exported. There are two scenarios here; oil as a final good for 
consumption and oil as an intermediate good. We first consider oil as a final good for consumption. If the source of the boom is an exogenous rise in world prices and the increase in prices is allowed to pass through to domestic prices then the increase in factor income in the oil sector as a result of the boom might be eroded by the increase in prices for domestic consumption of oil - the net spending effect will be less. However if domestic prices are subsidized as is the practice in most oil producing countries then there will still be a positive net spending effect as a result of the boom. Next we consider oil as an intermediate good used as input for further production in the lagging sector or nontradable sector. Two substitution effects emerge here. There would be a resource movement between the lagging sector and the nontradable sector depending on which of the two is less oil-intensive and therefore more profitable. If the nontradable sector is less oil intensive, then it would produce a higher level of output at prevailing prices resulting in less real appreciation of the exchange rate. Both sectors would also tend to substitute for oil as an input for production over time.

Although extensive literature exists on the Dutch disease phenomenon, they broadly fall into three main categories; those that focus on the spending effect only and the resultant spillover effect on one hand, those that focus on the resource movement effect and its resultant spillover effects on the other hand or both. Additionally, existing literature mainly address the short run effects of a resource boom or aid inflows on other sectors of the economy, ignoring long run effects or dynamic effects over time. A few authors (e.g. Buiter and Purvis (1982); Aoki and Edwards (1982); Krugman (1987)) have addressed to some extent the static nature of the core model and subsequent literature that followed mostly under fixed exchange rate regimes.

This paper therefore adds to scarce literature on the Dutch disease phenomenon within a dynamic framework by assessing the impact of the oil industry (as measured by oil rents) on the output of a lagging sector - agriculture - in selected oil producing Middle Eastern and Northern African countries which operate flexible exchange rate regimes $^{\mathrm{a}}$. To investigate the long run effects we employ panel cointegration techniques by Pedroni (1999) and long ran panel granger causality tests of Canning and Pedroni (2008). The two-step system GMM by Blundell and Bond (1998) is then used to capture the dynamic short run speed of adjustment of agriculture value added

\footnotetext{
${ }^{\text {a }}$ Algeria, Egypt, Iran, Kuwait, Morocco, Saudi Arabia, Tunisia, United Arab Emirates
} 
back to equilibrium after a positive oil rent shock. Additionally this paper differs from existing literature by digressing its focus from a spending effect, resource effect or both, and addressing the absence of dynamic analysis in the Dutch disease literature. Furthermore most studies on oil booms have focused mainly on its effect on manufacturing and to a lesser extent agriculture (Corden, 1984), which is the focus of this paper. To further enrich the stock of literature on the Dutch disease phenomenon, we use estimation techniques that control for heterogeneity and cross sectional dependence of the countries in the panel.

The rest of the paper is structured as follows; section 2 reviews relevant literature, section 3 details the methodology, section 4 discusses empirical results and section 5 concludes.

\section{Relevant literature}

The seminal work of Corden and Neary (1982) specifically treated the cases of the Netherlands, Britain, Australia and other OPEC countries witnessing an increase in their financial resources generated by exports of natural resources which increased significantly over the 1960s and the 1970s. The authors found a pronounced deterioration of the trade balance and a real decrease in the revenues of specific manufacturing sectors in the studied countries. According to Corden and Neary (1982), the increase in energy prices led to a relative rise in the prices of tradable goods. As a result, the manufacturing industry was becoming increasingly less competitive and forced to adjust its production tempo and thus employment. At this stage, the authors reached their famous conclusion stating that the massive export of natural resources has a negative impact on both manufacturing industry and employment. Within a similar framework to that of the Corden and Neary (1982)' models, Buiter and Purvis (1982) and East wood and Venables (1982) concluded that the Dutch disease phenomenon results in an exchange rate appreciation in order to readjust the monetary market. It is especially for that reason; resource abundance may systematically affect the majority of other sectors in the economy. In an interesting contribution, Bruno and Sachs (1982), Aoki and Edwards (1982) and Krugman (1987) have addressed the theoretical shortcomings in earlier models proposed by Corden and Neary (1982) and Buiter and Purvis (1982) namely revolving around their static nature that cannot perfectly explore the dynamic effects of higher wealth on the 
tradable and non-tradable goods sectors. Thus, these authors have tried to rectify the earlier models by focusing at once on: (1) short term specificity of capital and its long-term mobility between the two good sectors; (2) capital accumulation in the aggregates; (3) international capital mobility; (4) far-sighted behavior by firms; (5) the role of external and internal dynamic economies of scale and; (6) households in their investment, consumption and savings decisions. It stands to reason that the impact of this phenomenon can affect agricultural sector for several factors. First, agricultural production techniques in some countries are found to be energy-intensive. Higher energy prices should raise the cost of production, leading to lower output and lower farm income. Second, agriculture is linked to other sectors through flows of intermediate inputs. Finally, the oil boom can result in neglecting the agricultural sector; see, inter alia, Hanson, Robinson and Schluter (1993) and Ammani (2011). Although the effects of the Dutch disease phenomenon on agricultural sector may be considered as being straightforward, it has been studied to a much lesser extent than the effect of this phenomenon on the manufacturing industry. Egg, Lerin and Tubiana (1985) showed that the proliferation of oil rent based economies in the 1970s and their increasing participation in global economic exchanges generate a number of established ideas about the global food system. The oil-producing countries are scarcely different from the majority of developing countries that have been seen to steadily increase over the past decades, the deficit in food and often deepening structural crisis in agriculture. As pointed by Egg et al. (1985) the oil rent distribution model seems to have systematically favored urban and import sectors at the expense of rural and domestic production. In the agricultural sector, even more than for other economic activities, the states whose financial power (and thus political and economic ones) has increased significantly have been unable to get around the spontaneous effects of rent diffusion in national economies. Even worse, they could not manage in a balanced way the domestic and international arbitration nor could they handle the relationship between modern enclaves, made with a great deal of capital, and existing circuits of production and circulation of agricultural products. Benjamin, Devarjan and Weiner (1989) have shown that the agricultural sector in Cameroon faces stiff competition from other primary exporters and hence the real exchange rate appreciation causes it to contract. However, the authors stressed that this result does not necessarily justify policy intervention. 
Indeed, government intervention to mitigate the DD phenomenon depends on whether the traded goods sectors confer certain benefits on the economy. It would be therefore necessary to show some divergence between private and social valuations before any remedy could be proposed. Fardmanesh (1991) analyzed the oil world-price (and therefore the world price of manufacturing) effect on two sides. On the supply side, the increase in the world price of manufacturing raises the value added, hence, the relative profitability of this sector in the developing oil-exporting countries. The manufacturing sector expands at the expense of the non traded and agricultural goods sectors. On the demand side, the increase in the world price of manufacturing lowers the developing oil exporting country's non oil terms of trade since it is an importer of manufactured goods. The resulting decline in its national income leads to an excess supply of non traded goods contracting this sector and expanding the traded goods sector. Also, the rise in the price of manufacturing can generate a substitution effect leading to an excess demand for the non traded goods expanding this sector and contracting the agricultural sector. It is arguably in this framework that we can classify the studies that have examined the impact of oil prices on the agricultural sector. At this level, we refer to, among others, Naszlioglu (2011) who found a unidirectional causality running from the world oil to three key agricultural commodity prices(corn, soybeans, and wheat) using Diks and Panchenko' (2006) nonlinear causality. Likewise, Nazlioglu and Soytas (2012), having used panel cointegration and Granger causality methods for a panel of twenty four agricultural products, found strong evidence for the impact of world oil prices on prices of several agricultural commodities contrary to the findings of many studies in the literature that report neutrality of agricultural prices to oil price changes.

\section{Methodology}

This section presents the empirical model that investigates the long-run impact of oil rents on agricultural value added. The long-run equation yields:

$$
a v a_{i t}=\alpha_{i}+a_{1 i} \text { oilr } r_{i t}+\varepsilon_{i t}
$$

where $i=1, \ldots, N$ for each country in the panel, $t=1, \ldots, T$ refers to the time period, ava is agricultural value added and oilr is oil rents. The parameter $\alpha_{i}$ allows for the possibility of country-specific fixed effects. Finally, $\varepsilon$ is defined as the error term. 
Equation (1) is the long-run or steady-state equation, which provides the residuals necessary to estimate the short-run adjustment processes.

The Canning and Pedroni (2008) methodological approach considers a dynamic Error Correction (EC) model within a panel data framework. The EC model employed yields:

$$
\begin{aligned}
& \Delta a v a_{i t}=\beta_{1 i}+\sum_{j=1^{`}}^{k} \beta_{11 i j} \Delta a v a_{i t-j}+\sum_{j=1}^{k} \beta_{12 i j} \Delta o i l r_{i t-j}+\lambda_{1 i} \varepsilon_{i t-1}+\eta_{1 i t} \\
& \Delta o i l r_{i t}=\beta_{2 i}+\sum_{j=1^{\prime}}^{k} \beta_{21 i j} \Delta a v a_{i t-j}+\sum_{j=1}^{k} \beta_{22 i j} \Delta o i l r_{i t-j}+\lambda_{2 i} \varepsilon_{i t-1}+\eta_{2 i t}
\end{aligned}
$$

where $\Delta$ is the first differences factor, $\mathrm{k}$ is the parameter associated with the optimal number of lags in the EC model, $\varepsilon$ are the EC terms (i.e., the residuals from the cointegration regression-equation (1)), and $\beta_{i s}, \beta_{i j s}$ and $\lambda s$ are the coefficients to be estimated. Finally, $\eta s$ are the error terms associated with the EC equations. The remaining variables are defined as in equation (1). Equations (2) and (3) describe the short and long run relations between the variables under study here, i.e. changes in agricultural value added and changes in oil rents. At the same time, these equations include the residuals from the steady-state equilibrium as specified in equation (1). In other words, we have added dynamics, through the $\lambda s$ coefficients, to show how agricultural value added moves towards the long-run equilibrium following explicit shocks in oil rents. Moreover, the long-run coefficients $\lambda s$ measure the speed of adjustment to long-term equilibrium. The higher these coefficients are, the faster the adjustment to long-run equilibrium is.

\section{Data and Empirical results}

We use annual data from 1970 to 2011 on oil rents and agriculture value added in this paper. Data on both variables is sourced from the world development indicators of the World Bank. The order of integration of the variables is ascertained using a number of panel unit root tests. The essence is to see whether the variables are integrated of the same order to in order to undertake panel cointegration tests. The panel based Augmented Dickey Fuller (ADF) (1979) test proposed by Levin et al. (2002) - the LLC tests - assumes homogeneity in the dynamics of the autoregressive coefficients 
for all panel units. Alternatively, Maddala and Wu (1999) employ nonparametric methods in conducting panel unit root tests with the Fisher (1932) - ADF and FisherPhillips-Perron (1988) tests which has the advantage of allowing for as much heterogeneity across units as possible. Under the Levin et al. (2002), Fisher-ADF, and Fisher-PP tests the null hypothesis is a unit root and the alternative hypothesis is no unit root. The panel unit root tests, shown in Table 1, reveal that each variable is integrated of order one. These results hold both on an overall sample basis and across regions. The panel unit root results recommend the potential presence of panel cointegration, which we perform next.

Table 1: Panel unit root tests

\begin{tabular}{llll}
\hline Variables & LLC Test & Fisher - ADF Test & Fisher - PP Test \\
\hline ava & -0.92 & 19.63 & 21.08 \\
$\Delta$ ava & $-7.38^{*}$ & $86.51^{*}$ & $104.52^{*}$ \\
oilr & -0.86 & 17.49 & 19.29 \\
$\Delta$ oilr & $-7.54^{*}$ & $82.26^{*}$ & $98.72^{*}$ \\
\hline
\end{tabular}

Notes: Panel unit root tests include intercept and trend. LLC is the Leven et al. panel unit root test, while Fisher-ADF and Fisher-PP are the two versions of the Maddala and Wu panel unit root test. An * denotes statistical significance at $5 \%$ meaning rejection of the null hypothesis of non-stationarity.

The Pedroni (1999) heterogeneous panel cointegration test, which allows for crosssectional interdependence with different individual effects, is estimated to determine whether a long-run equilibrium relationship exists ${ }^{\mathrm{b}}$. The Pedroni (1999) methodology takes heterogeneity into account using specific parameters which are allowed to vary across individual countries of the sample. Pedroni (1999) developed seven tests based on the residuals from the cointegrating panel regression under the null hypothesis of non-stationarity. The first four tests (panel $v$-stat, panel rho-stat, panel pp-stat, panel adf-stat) are based on pooling the data along the within-dimension that are known as the panel cointegration statistics. The next three tests (group rho-stat, group pp-stat, group adf-stat) are based on pooling the data along the between dimension and they are denoted group mean cointegration statistics. All tests are calculated using the estimated residuals from panel regression (1). These statistics are based on averages

\footnotetext{
${ }^{\mathrm{b}}$ The Pesaran (2003) test for cross sectional dependence rejects the null hypothesis that cross sections are independent. Pesaran and Yamagata (2008) tests and Swamy (1970) test also reject the null hypothesis of slope homogeneity across the countries in the panel. Details are available from the authors on request.
} 
of the individual autoregressive coefficients associated with the unit root tests of the residuals for each country in the panel.

Pedroni test process obtained from equation (1) has been tested according to the following process:

$\varepsilon_{i t}=\rho_{i} \varepsilon_{i t-1}+\mu_{i t}$

Pedroni presents test statistics with different methods of cointegration of $\rho_{i}=1$. There are two groups of tests: one harmonized theory in which $\rho_{i}=\rho<1$ for all $\mathrm{i}_{\mathrm{s}}$. This group of tests may provide convergence possibility among countries. The other nonharmonized theory means $\rho_{i}<1$ is for each $i$ test or group statistics for nonconvergence situation among countries. It is worth mentioning that the key difference between both pooled and group tests is that the residuals test is grouped rather than pooled. Group mean tests are preferred over the pooled tests since they allow greater flexibility under alternative hypotheses. Table 2 reports both the panel and group mean panel cointegration test statistics. All seven test statistics reject the null hypothesis of no cointegration at the $1 \%$ significance level. In other words, the results reveal that there is a long-run association between agricultural value added and oil rents across our panel countries. This reveals that agricultural value added has a long run relation with oil rents across the eight countries in our panel set. The panel cointegration findings point out the presence of Granger causality as well. In pursuit of testing for causality we also plan to explore the direction and sign of causality, which is not known.

To identify the direction and sign of causality, the panel causality test developed by Canning and Pedroni (2008) is employed. This particular test makes use of the corresponding panel cointegration error correction model as specified in equations (2) and (3). 
Table 2: Pedroni (1999) Panel cointegration tests

\begin{tabular}{lr|ll}
\hline Panel Test Statistics & & Group Mean Panel Test Statistics & \\
\hline Panel v-statistic & $41.25^{*}$ & Group $\rho$-statistic & $-42.98^{*}$ \\
Panel $\rho$-statistic & $-40.94^{*}$ & Group PP-statistic & $-43.71^{*}$ \\
Panel PP-statistic & $-40.47^{*}$ & Group ADF-statistic & $-7.80^{*}$ \\
Panel ADF-statistic & $-7.89^{*}$ & & \\
\hline
\end{tabular}

Notes: All reported values are distributed as a Typical Normal distribution [i.e., N(0,1)] under the null of unit root or no co-integration. Panel stats are weighted by long-run variances. An '*' denotes the rejection of the null hypothesis of no cointegration at the 1 percent significance level.

After identifying a lag order of 2 , the coefficients $\lambda_{1}$ and $\lambda_{2}$ show the speed of adjustment to equilibrium. In order to get the presence of the long-run relationship, Granger causality implies that at least one of the $\lambda$ coefficients must be different from zero. According to the test of Canning and Pedroni (2008), the null hypothesis is that there is no panel Granger causality. They report two tests in order to investigate the validity of the null hypothesis. First, they report the Group Mean (GM) test- $\lambda_{1}$, which yields:

$\overline{\lambda_{1}}=\sum_{i=1}^{N} \lambda_{1 i} / N$

where $\mathrm{N}$ denotes the number of countries in the panel and $\lambda_{1 \mathrm{i}}$ is the estimated EC coefficient from equation (2) across all countries in the panel. Next, they report the joint panel Test Statistic (TS), which yields:

$\overline{t_{\lambda 1}}=\sum_{i=1}^{N} t_{\lambda 1 i} / N$

with $\mathrm{N}$ being (again) the number of countries in the panel, and $t_{\lambda 1}$ is the individual country test for the null hypothesis that renewable energy consumption does not Granger cause GDP, i.e. $\lambda_{1 \mathrm{i}}=0$. The test statistic has a standard normal distribution. The second test they develop is the Lambda-Pearson (LP) panel test, which yields:

$p_{\lambda 1}=-2 \sum_{i=1}^{N} \ln p \lambda_{2 i}$

where $\operatorname{lnp} \lambda_{2 i}$ is the $\log$ of the $\mathrm{p}$-value coming from the $t$-test statistic used to test the null hypothesis that agricultural value added does not Granger cause oil rents. This 
test combines p-values associated with each of the individual countries that make up the panel. The LP statistic follows a chi-square distribution with $2 N$ degrees of freedom. For each country $i$ if a causal connection oilrs $s_{i t} \rightarrow a v a_{i t}$ exists, then the sign of the long run impact is equal to $\left(-\lambda_{1} / \lambda_{2}\right)$. The estimates for $\lambda_{1 \mathrm{i}}$ and $\lambda_{2 \mathrm{i}}$ are normally distributed, so the ratio will be distributed Cauchy. Canning and Pedroni (2008) develop a bootstrap test based on the median of these ratios. The sign on $-\lambda_{1} / \lambda_{2}$ is expected to have the same sign as the long-run effect of oil rents on agricultural value added. In other words, this particular coefficient is considered as a test of the impact of the long-run as well as a test of the sign of that long-run effect. Table 3 reports the long-run Granger causality tests.

Table 3: Long-run panel Granger causality tests.

\begin{tabular}{llll|llll}
\hline Test & $\lambda_{1}$ & GM & LP & $\lambda_{2}$ & GM & LP & $\operatorname{Sign}\left(-\lambda_{1} / \lambda_{2}\right)$ \\
\hline Total & -0.16 & $-4.93^{*}$ & $83.05^{*}$ & -0.217 & $-4.52^{*}$ & $98.74^{*}$ & $-0.48(0.12)$ \\
\hline
\end{tabular}

Notes: $\lambda_{1}=$ oilr causes ava, $\lambda_{2}=$ ava causes oilr. The figure in parenthesis denotes standard errors. An '*' denotes statistical significance at $1 \%$ level.

The results show that:

- In terms of panel long-run causality running from oil rents to agricultural value added, both GM and LP statistics recommend the rejection of the null hypothesis of no Granger causality at the $1 \%$ significance level.

- In terms of the sign effect based on the ratio of lambda coefficients reported in the last column of Table 3, the evidence reveals a negative sign.

- Finally, in terms of the panel long-run Granger causality running from agricultural value added to oil rents, once again both tests document the rejection of the null hypothesis of no Granger causality at the $1 \%$ significance level.

These causality tests can inform us about the sign of the oil rents effect in the longrun. The negative sign of the lambda ratio suggests that higher oil rents leads to lower levels of agricultural value added in the long run. There is also a negative reverse causality from agriculture value added to oil rents. This indicates that a boom to one sector has a contractionary effect on the other sector. Hence, a rise in oil rents leads to a reallocation of resources from the agricultural sector to the oil sector. This results in 
a fall in output of the agricultural sector and consequently its value addition to total output. This serves as evidence of a Dutch disease effect of an expansion in oil production on agriculture in the MENA countries in this panel. Although it is not clear whether the increase in oil rents emanate from an exogenous price increase or an increase in production, it is clear that the two variables have a negative long run relationship, indicating that an increase in oil rents is associated with a contraction of the agriculture sector in these countries in the long run.

\subsection{Error Correction estimates and the short-run adjustment}

To explore the short-run dynamics between ava and oilr we apply GMM estimation. GMM estimation circumvents the bias associated with including a lagged dependent variable as a regressor and enables us to calculate consistent and efficient estimates. In particular, we use the two-step System GMM estimators developed by Blundell and Bond (1998). It combines the regression in differences with the regression in levels in a system and uses additional instruments in levels. The moment conditions of the instruments can be verified using the Sargan statistic that tests the validity of all instruments.

$$
\begin{aligned}
& \Delta a v a_{i t}=f_{1 i}+a_{1} \Delta a v a_{i t-1}+a_{2} \Delta o i l r_{i t}+a_{3} \Delta o i l r_{t-1}+a_{4} \Delta o i l r_{t-2}+\lambda_{1 i} \varepsilon_{i t-1}+\mu_{1 i t} \\
& \Delta o i l r_{i t}=f_{2 i}+a_{5} \Delta o i l r_{i t-1}+a_{6} \Delta a v a_{i t}+a_{7} \Delta a v a_{i t-1}+a_{8} a v a_{i t-2}+\lambda_{2 i} \varepsilon_{i t-1}+\mu_{2 i t}
\end{aligned}
$$

The results of the corresponding error-correction regressions are summarized in Table 4. They include the coefficients of the regressions, the summation of the short-run effects with the corresponding Engle (1983) Wald test $p$-values, and the Sargan (1958) tests. To verify GMM consistency, we have to make sure that the instruments are valid. We use the Sargan test of over-identifying restrictions to test the validity of the instrumental variables. The null hypothesis assumes that the orthogonality conditions of the instrumental variables are satisfied. The short-run effect can be divided into the effect of the lagged dependent variable and that of the independent variable. The short-time adjustment of the independent variable is measured by the 
effect of the contemporaneous and lagged change of the independent variable. The significance of the summarized short-run effects, which is simply the sum of the two coefficient values, is tested via a Wald test.

Table 4 : EC estimates (ava equation)

\begin{tabular}{l|l}
\hline Coefficients & Dava \\
\hline $\mathrm{a}_{2}$ & -0.25 \\
& $(-4.58)^{*}$ \\
$\mathrm{a}_{3}$ & -0.13 \\
& $(-5.36)^{*}$ \\
$\mathrm{a}_{4}$ & -0.06 \\
& $(4.94)^{*}$ \\
Summation Wald Test $\left(\mathrm{a}_{2}+\mathrm{a}_{3}\right)$ & -0.38 \\
p-value & 0.000 \\
Sargan Test $(p$-value) & 0.863 \\
\hline Notes: Figures in parentheses denote t-statistics. * denotes significance at $1 \%$
\end{tabular}

Notes: Figures in parentheses denote t-statistics. $*$ denotes significance at $1 \%$

The short run EC estimates indicates a negative significant causal effect from oilr on ava in the short run. The short run coefficient estimates measure the short run speed of adjustment of $a v a$ back to equilibrium after an oil rent shock, hence they are negatively signed. The negative and low coefficients indicate a slow rate of adjustment back to equilibrium in the short run. The summation Wald test statistic results show that the short run adjustment of the independent variable is significant at $1 \%$ level. As per the Sargan Test statistic we also fail to reject the null that overidentification restrictions are valid, meaning the instrument set is exogenous.

\section{Conclusion}

This paper examines the impact of an oil sector boom on agriculture value added in selected Middle Eastern and North African (MENA) countries from the period 1970 to 2011. We use panel cointegration tests by Pedroni (1999) to establish a long run relationship between oil rents and agriculture value added. We find a negative long run relationship between oil rents and agriculture value added in the countries studied. This implies that a boom to the oil sector in these countries is associated with a contraction of the agriculture sector in the long run. We further employ long ran panel causality tests by Canning and Pedroni (2008) to establish the direction of causality between oil rents and agriculture value added, the impact and sign of this long run effect. We find negative long run reverse causality between oil rents and agriculture 
value added, confirming that a boom to one sector would result in a contraction of the other sector. To establish the short run adjustment of agriculture value added back to equilibrium after an oil rent shock, we employ two-step System GMM method by Blundell and Bond (1998). The results show a rather slow rate of short run adjustment of ava back to equilibrium after a boom in oil rents.

The results of this study therefore indicate that a boom in oil rents is associated with a contraction of the agriculture sector in the countries in this study, holding all other determinants of agriculture sector output constant. The rate of adjustment of the agriculture sector back to equilibrium is also found to be slow as depicted by the short run speed of adjustment coefficients. This serves as evidence of a Dutch disease effect of an oil sector boom on agriculture in the MENA countries in this study, and a slow rate of adjustment of the agriculture sector back to equilibrium. The implications of this finding for policy makers in these countries would depend on whether there are significant social benefits from the traded sector as compared to private benefits on their economies as a whole. It would therefore be necessary to evaluate social and private benefits of the traded sector to ascertain if there is a net benefit or a net loss of this Dutch disease phenomenon in these countries. In countries where there is a net benefit at the expense of reduced agriculture value added there might not be the need to any policy interventions. However in countries where there is a net loss there would be the need for relevant policy interventions. These interventions would depend on whether the net loss is caused by a resource movement effect or spending effect and their attendant spillover-loss effects.

To mitigate the resource movement effect countries like Norway which successfully avoided the resource curse in the 70 s had a centralised wage system linked to the productivity of the non-booming sector, in this case manufacturing (Larsen, 2004). This was backed by a nationally driven policy stance to drive manufacturing or industrialisation as the source of economic growth. However Norway's success was also favoured by the fact that their oil discovery was in the North Sea and not in-land as in Middle-Eastern countries. Consequently its extraction was more capital and technology intensive than labour intensive. This minimised the mobility of labour from other sectors towards the extractive sector and the shrinking of the non-booming sectors of the economy (Larsen, 2004). Policy interventions to address the spending 
effect are influenced by who owns the rent from the resource extraction. If rents accrue to Government as opposed to the private sector or elite class, then fiscal discipline, growth inducing expenditure and international investments could mitigate the appreciating effect of the rents on domestic currency. In that respect countries have invested oil rents into developing other productive sectors of the economy, which usually account for a larger portion of the labour force than the natural resource sector which usually leads to jobless growth (Cappelen, Eika and Holm, 2000).

Third, research has shown that artificial stabilisation of exchange rates in response to the Dutch disease phenomenon is highly distortionary and ineffective (Lama and Medina, 2012). Consequently it has become a recent practice to keep natural resource earnings in offshore accounts and invest them in international capital markets, repatriating them as and when needed. This prevents the buildup of excessive foreign exchange reserves which minimizes the appreciating impact of the resource rents on the local currency of the resource endowed country. Additionally Larson (2004) found that specific macroeconomic policy interventions, the quality of political and economic institutions, a strong and independent judicial system, and social norms have contributed to Norway's ability to escape the resource curse and the Dutch disease for more than two decades. Furthermore, other authors (Auty (2001); Gylfason (2001); Sachs and Warner (2001); Torvik (2002)) found that rent seeking and corruption are core elements of what causes the resource curse. Thus democratic, transparent and accountable institutions that ensure low levels of corruption and equitable distribution of natural resource rents would lead to greater social benefits of natural resource rents and are effective in addressing the Dutch disease phenomenon. It is also logical to expect that the policy pathways to address this phenomenon could differ between the countries in this panel although the ultimate policy objective might be the same.

\section{References}

Acosta, A.P., Lartey, E.K.K., Mandelman, S.F., 2007. Remittances and the Dutch Disease. Federal Reserve Bank of Atlanta Working Paper 2007-08. 
Neglected? International Journal of Statistics and Applications 1(1), 6-9.

Aoki, M., Edwards, S., 1983. Export boom and Dutch disease: a dynamic analysis. Resources and Energy 5(3), 219-42

Auty, R. M., 2001. The Political Economy of Resource-Driven Growth, European Economic Review 45(4-6), 839-846

Benjamin, N.C., Devarjan, S., Weiner, R.J., 1989. The Dutch disease in a developing country. Oil Reserves in Cameroon, Journal of development economics 30, 71-92.

Blundell, R., Bond, S., 1998. Initial conditions and moment restrictions in dynamic panel data models, Journal of Econometrics 87, 115-143.

Bruno, M., Sachs, J., 1982. Energy and resource allocation: a dynamic model of the " Dutch Disease", The Review of Economic Studies XLIX, 845-859.

Buiter, W.H., Purvis, D.D., 1982. Oil, disinflation and export competitiveness: a model of the Dutch disease, in Bhandari, J. and Putnam, B. (eds.), Economic Interdependence and Flexible Exchange Rates, Cambridge, Mass., MIT Press.

Canning, D., Pedroni, P., 2008. Infrastructure, long-run economic growth and causality tests for cointegrated panels. The Manchester School (76), 504-27.

Cappelen, A., Eila, T., Holm, I., 2000. Resource booms: Curse or Blessing? Article presented at the Annual Meeting of American Economic Association Economic Association, Discussion paper series 2004, Oslo: Statistics Norway.

Corden, W.M., 1984. Booming Sector and Dutch disease Economics. Survey and Consolidation. Oxford Economics Papers, 36(3),359-380

Corden, W. M., Neary J. P., 1982. Booming Sector and Deindustrialization In A Small Open Economy, The Economic Journal, 825-848.

Dickey, D. A., Fuller, W. A., 1979. Distribution of the Estimators for Autoregressive Time Series with a Unit Root. Journal of the American Statistical Association 74, 427-431.

Diks, C., Panchenko, V., 2006. A new statistic and practical guidelines for nonparametric granger causality testing. Journal of Economic Dynamics and Control, 30(9-10), 1647-69.

Eastwood, R.K., Venables, A.J., 1982. The macroeconomic implications of a resource discovery in an open economy, Economic Journal, June, 285-99.

Engle, R. F., 1983. "Wald, Likelihood Ratio, and Lagrange Multiplier Tests in Econometrics". In Intriligator, M. D.; and Griliches, Z. Handbook of Econometrics II. 
Elsevier. pp. 796-801

Egg, J., Lerin, F., Tubiana, L., 1985. Rente pétrolière et crise agricole, Etudes Rurales 99/100, 231- 264.

Fardmanesh, M., 1991. Dutch disease economics and the oil syndrome: an empirical study, World Development 19, 711-717.

Fisher, R.A., 1932. Statistical Methods for Research Workers, Forth Edition, Edinburgh, Oliver and Boyd

Gylfason, T., 2001. Natural Resources, Education, and Economic Development, European Economic Review, 45, 847-859.

Hanson, K., Robinson, S., Schluter, G., 1993. Sectoral Effects of a World Oil Price Shock: Economywide Linkages to the Agricultural Sector, Journal of Agricultural and Resource Economics 18(1), 96-116.

Kruger, P., 1987. The narrow moving band, the Dutch disease and the competitive Consequences of Mrs Thatcher: Notes on trade in the presence of dynamic scale Economics. Journal of Development Economics, 27, 41-55

Lama, R., Medina, J.P., 2012. Is exchange rate stabilisation an appropriate cure for the Dutch Disease? International Journal of Central Banking 8(1), 5-46

Larson, E.R., 2004. Escaping the resource curse and the Dutch disease? When and why Norway caught up with and forged ahead of its neighbours. Discussion papers No. 377. Statistics Norway Research Department.

Levin, A., Lin, C.F., Chu, C., 2002. Unit root tests in panel data: asymptotic and finite-sample properties. Journal of Econometrics, 108, 1-24.

Maddala, G.S., Wu, S.A., 1999. Comparative study of unit root tests with panel data and a new simple test. Oxford Bulletin of Economics and Statistics 108, 1-24.

Meade, J., Russel, E., 1957. Wage Rates, The Cost of Living and the Balance of Payments. Economic Record 33, 23-28. In J. Meade and S. Howson (eds.) The Collected Papers of James Meade. Vol.3. Winchester, Mass., London and Sydney: Unwin Hyman.

Nazlioglu, S., 2011. World oil and agricultural commodity prices: Evidence from nonlinear causality, Energy Policy 39, 2935-43. 
Nazlioglu, S. Soytas, U., 2012. Oil price, agricultural commodity prices, and the dollar: A panel cointegration and causality analysis, Energy Economics 34, 1098- 104 Pedroni, P., 1999. Critical values for cointegration tests in heterogeneous panels with multiple regressors. Oxford Bulletin of Economics and Statistics 1999(61), 653-70.

Pesaran, H., 2003 A simple panel unit root test in the presence of cross sectional dependence. Cambridge Working Papers in Economics 0346. Faculty of Economics (DAE). University of Cambridge.

Pesaran, H., Yamagata, T., 2008. Testing slope homogeneity in large panels. Journal of Econometrics, Elsevier, 142(1), 50-93.

Phillips, P. C. B., Perron, P., 1988. "Testing for a Unit Root in Time Series Regression". Biometrika 75(2), 335-346

Sachs, J. D., Warner, A.M., 2001. The Curse of Natural Resources, European Economic Review, 45, 827-38.

Sargan, J. D., 1958. "The Estimation of Economic Relationships Using Instrumental Variables". Econometrica 26(3), 393-415

Swamy, P.A.V.B., 1970. Efficient inference in a random coefficient regression model.

Econometrica 38(2), 311-23.

Torvik, R., 2002. Natural Resources, Rent Seeking, and Welfare, Journal of Development Economics, 67, 455-70. 